\title{
Conformational flexibility in the enterovirus RNA replication platform
}

\author{
MEGHAN S. WARDEN, ${ }^{1} \mathrm{KAI}$ CAI, ${ }^{2}$ GABRIEL CORNILESCU, ${ }^{3}$ JORDAN E. BURKE, ${ }^{2,4} \mathrm{KOMALA} \mathrm{PONNIAH,}^{1}$ \\ SAMUEL E. BUTCHER, ${ }^{2}$ and STEVEN M. PASCAL ${ }^{1}$ \\ ${ }^{1}$ Department of Chemistry and Biochemistry, Old Dominion University, Norfolk, Virginia 23529, USA \\ ${ }^{2}$ Department of Biochemistry, University of Wisconsin-Madison, Madison, Wisconsin 53706, USA \\ ${ }^{3}$ National Magnetic Resonance Facility at Madison (NMRFAM), University of Wisconsin-Madison, Madison, Wisconsin 53706, USA
}

\begin{abstract}
A presumed RNA cloverleaf $\left(5^{\prime} \mathrm{CL}\right)$, located at the $5^{\prime}$-most end of the noncoding region of the enterovirus genome, is the primary established site for initiation of genomic replication. Stem-loop B (SLB) and stem-loop D (SLD), the two largest stemloops within the $5^{\prime} \mathrm{CL}$, serve as recognition sites for protein interactions that are essential for replication. Here we present the solution structure of rhinovirus serotype $145^{\prime} \mathrm{CL}$ using a combination of nuclear magnetic resonance spectroscopy and smallangle X-ray scattering. In the absence of magnesium, the structure adopts an open, somewhat extended conformation. In the presence of magnesium, the structure compacts, bringing SLB and SLD into close contact, a geometry that creates an extensive accessible major groove surface, and permits interaction between the proteins that target each stem-loop.
\end{abstract}

Keywords: RNA; enterovirus; replication; NMR; SAXS; cloverleaf

\section{INTRODUCTION}

Enteroviruses are responsible for a number of diseases and conditions ranging from poliomyelitis to the common cold (Greenberg 2003). Their genetic information is carried as a small single-stranded RNA molecule $(\sim 7.5-8.3 \mathrm{~kb})$ that is replicated through a highly conserved mechanism (Goodfellow et al. 2003). The genome consists of three distinct sections: an extensive $5^{\prime}$ noncoding region (NCR) and a much smaller $3^{\prime}-\mathrm{NCR}$, that together flank a large single open reading frame. This open reading frame encodes a single large polyprotein ( $250 \mathrm{kDa})$. After translation, the polyprotein is systematically cleaved into a dozen or so structural and nonstructural proteins by virus-encoded proteases that are part of the polyprotein. The $3 \mathrm{C}$ protease is responsible for most of the cleavage events. In addition, a population of the $3 \mathrm{C}$ protease molecules remain covalently joined to the virus-encoded RNA-dependent RNA polymerase (3D), forming the fusion protein 3CD. The 3CD protein interacts directly with the $5^{\prime}-\mathrm{NCR}$ as an essential step in the replication process (Andino et al. 1990; Jacobson et al. 1993; Agol et al. 1999; Goodfellow et al. 2000).

The 5'-NCR can be further subdivided into two regions. A large ( 400-500 bases) internal ribosome entry site

\footnotetext{
${ }^{4}$ Present address: Department of Biochemistry and Biophysics, University of California-San Francisco, San Francisco, California 94143, USA

Corresponding author: spascal@odu.edu

Article is online at http://www.rnajournal.org/cgi/doi/10.1261/rna. 069476.118.
}

(IRES) is immediately $5^{\prime}$ to the ORF, where it directs translation of the polyprotein without the need for a capped mRNA structure. At the extreme 5 '-end of the genomic RNA, a smaller ( 83 base) region, predicted to form a cloverleaf structure $\left(5^{\prime} \mathrm{CL}\right)$ in enteroviruses, serves as the main replication platform for virus replication (Rivera et al. 1988; Pilipenko et al. 1989; Le and Zuker 1990; Gamarnik and Andino 1997). Sequence analysis of the $5^{\prime} \mathrm{CL}$ predicts the presence of one stem (stem A or SA) and three stem-loops (SLB, SLC, and SLD) (see Fig. 1). SLD attracts the fusion protein $3 C D$, delivering the $3 D$ polymerase to the required site to begin synthesis of a negative strand RNA (Andino et al. 1990). This negative strand then serves as a template to produce multiple copies of the positive strand, which can be used as either additional mRNA or genetic material for nascent viral particles that are released from the cell and can go on to infect other cells.

The loop region of SLB contains a C-rich sequence that attracts the host poly(C)-binding protein (PCBP). PCBP functions both in translation, via binding to $\mathrm{C}$-rich regions in the IRES, and in replication, via binding to the $5^{\prime} C L$ SLB (Gamarnik and Andino 1997; Parsley et al. 1997). However, when PCBP is attached to the IRES, PCBP can be cleaved

(C) 2019 Warden et al. This article is distributed exclusively by the RNA Society for the first 12 months after the full-issue publication date (see http://rnajournal.cshlp.org/site/misc/terms.xhtml). After 12 months, it is available under a Creative Commons License (Attribution-NonCommercial 4.0 International), as described at http:// creativecommons.org/licenses/by-nc/4.0/. 


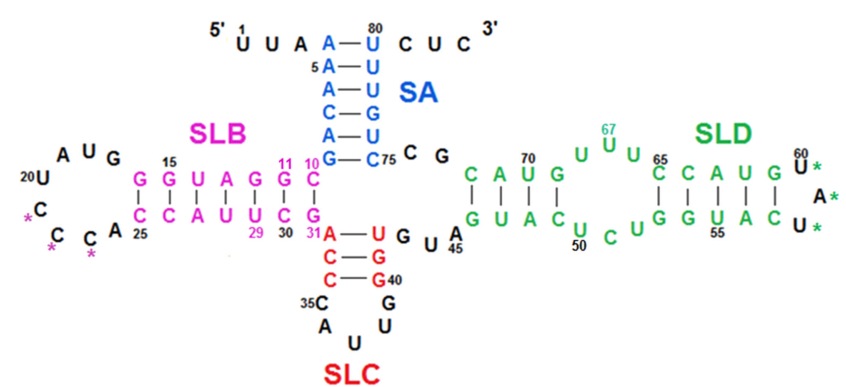

FIGURE 1. Secondary structure prediction of RV-B14 $5^{\prime} \mathrm{CL}$. The RV$B 145^{\prime} \mathrm{CL}$ is predicted to form a four helix junction containing stem A (SA; blue), stem-loop B (SLB; magenta), stem-loop C (SLC; red), and stem-loop D (SLD; green). Protein binding sites in SLB (magenta stars) and SLD (green stars) are shown, along with colored numbering for key nucleotides discussed in the text.

by the virus-encoded 3 C protease. The cleaved PCBP can then only function in replication. Thus, cleavage of IRESbound PCBP serves effectively as a switching mechanism from translation to replication (Andino et al. 1990, 1993; Blyn et al. 1996, 1997; Barton et al. 2001). Furthermore, the binding of PCBP to SLB facilitates the binding of $3 C D$ to SLD and triggers circularization of the RNA genome, two events that are essential for the synthesis of the negative strand (Gamarnik and Andino 1998). A better understanding of the structural basis of these interactions and their interdependence could lead to ways to inhibit virus replication, leading to effective treatment or immunization against the large number of diseases and conditions associated with enterovirus infection.

In this study, a combined nuclear magnetic resonance (NMR) and small-angle X-ray scattering (SAXS) approach has been used to determine the solution structure of the $5^{\prime} \mathrm{CL}$ RNA from serotype 14 of the rhinovirus (RV-B14). Results show that the cloverleaf conformation, in particular its compactness, conformational stability, and relative orientation of the two largest stem-loops (SLB and SLD), is highly dependent upon the absence versus presence of magnesium. This study represents an important step in the process of building a high-resolution structural understanding of enterovirus replication.

\section{RESULTS}

\section{NMR analysis of RV-B14 5'CL}

\section{Peak assignments}

Imino protons, which are present only in guanine (G) and uracil (U) bases, are highly exchangeable with solvent protons. Therefore, the presence of the imino resonance implies protection, most notably via hydrogen bonding in a stable base pair. The absence of an imino resonance conversely suggests the absence of a stable hydrogen bond and is often indicative of presence in a dynamic loop or bulge region. Resonances of imino protons in a WatsonCrick base pair range from $\sim 11.5-13$ ppm $(G)$ and $~ 13-$ 15 ppm (U). Resonances observed outside of the above spectral range indicate the presence of a non-WatsonCrick base pair, such as a GU (10-12 ppm) or a UU base pair (10.4-11.3 ppm).

The RV-B14 5'CL molecule contains a total of 45 imino protons, 26 of which were observed in the two-dimensional ${ }^{1} \mathrm{H},{ }^{1} \mathrm{H}-\mathrm{NOESY}$ spectrum (Fig. 2) in the absence of magnesium. Five strong resonances are located outside the spectral range of a Watson-Crick base pair and were assigned to nucleotides U50, U52, U66, U68, and G12 as described below. In general, imino proton resonances were assigned based on sequential imino-imino NOESY cross-peaks (Fig. 2), with the assistance of imino proton resonance assignments from previously published works with isolated RV-B14 SLB (Warden et al. 2017) and SLD (Headey et al. 2007). The observed pattern of sequential imino-imino NOE cross-peaks confirmed the formation of SA, SLB, SLC, and SLD helices, and the absence of additional imino resonances indicated nucleotides that are not involved in stable hydrogen bonding (for a full list of the hydrogen bond constraints, see Materials and Methods).

\section{Chemical shift changes upon incorporation into cloverleaf}

The imino chemical shift difference between SLB and SLD in previously described isolated stem-loops (Headey et al. 2007; Warden et al. 2017) versus when incorporated into the $5^{\prime} \mathrm{CL}$ (without magnesium) are shown in Figure 3A. The differences are small (RMSD 0.028 ppm),

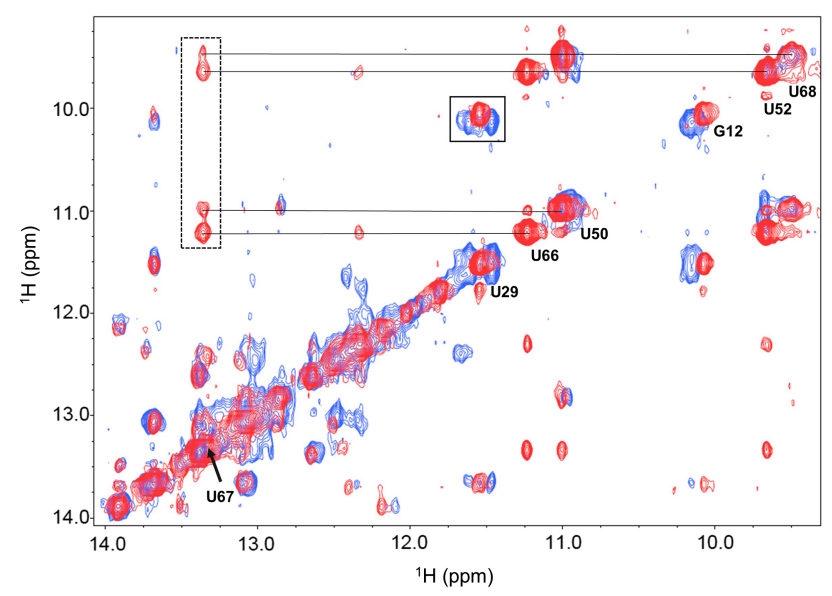

FIGURE 2. $2 \mathrm{D}{ }^{1} \mathrm{H},{ }^{1} \mathrm{H}-\mathrm{NOESY}$ of RV-B14 $5^{\prime} \mathrm{CL}$. Imino NOESY spectra in the absence (blue) and presence (red) of magnesium. The multiple resonances for nucleotide $\mathrm{U} 29$ in the absence of magnesium (solid box) collapse to a single resonance in the presence of magnesium. The imino resonance of nucleotide U67 is only observed upon the addition of magnesium, with sequential imino-imino cross-peaks to U67 shown in the dashed box. 


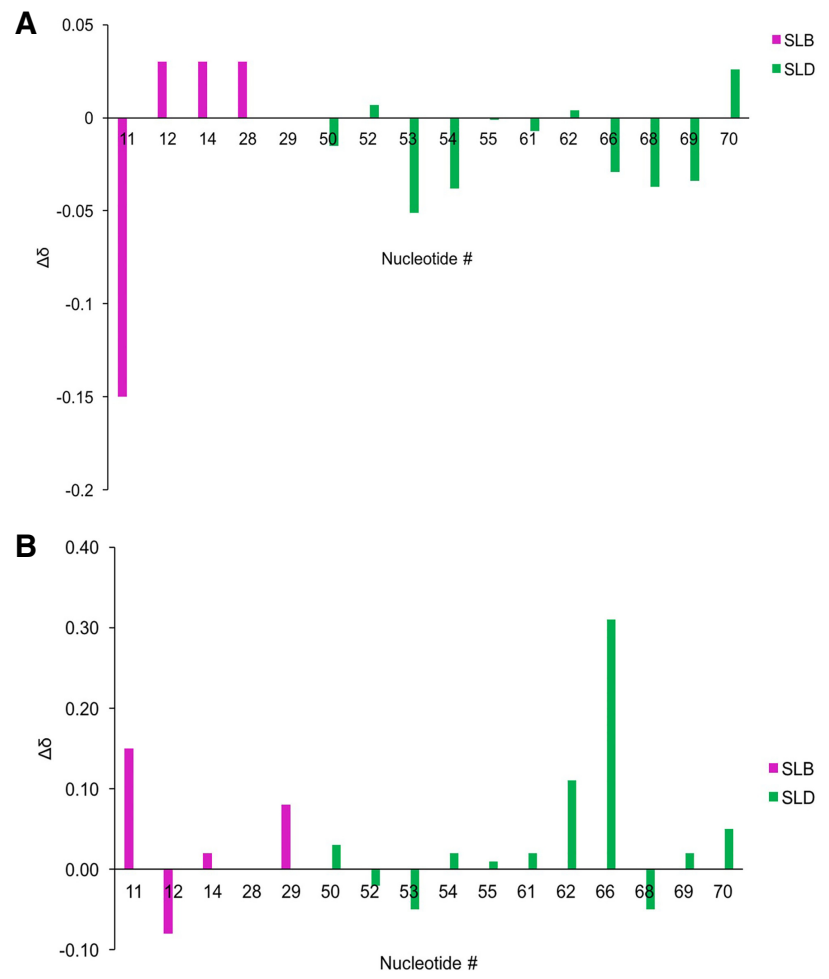

FIGURE 3. Chemical shift differences for RV-B14 $5^{\prime} \mathrm{CL} .{ }^{1} \mathrm{H}$ chemical shift changes within SLB (magenta) and within SLD (green) induced by incorporation into the $5^{\prime} \mathrm{CL}(A)$ in the absence of magnesium and $(B)$ in the presence of magnesium.

consistent with conservation of the structure, excluding the large difference observed for G11. Also, a new peak appears for the $\mathrm{G} 31$ imino resonance, indicating stabilization of the $\mathrm{C} 10-\mathrm{G} 31$ base pair only in the $5^{\prime} \mathrm{CL}$, and not in the isolated SLB. This effectively extends SLB by one base pair, matching the predicted length of SLB (see Fig. 1). This additional base pair evidently alters the chemical shift of the adjacent $\mathrm{G} 11$ resonance. In addition, the imino resonance of U29 appears to split into two or more resonances in the cloverleaf (Fig. 2), suggesting the presence of two or more slowly interconverting states, which was not observed in the isolated SLB structure. Since U29, G11, and G31 are from sequential base pairs at the junction end of SLB, it appears that alterations are localized to this region. To incorporate these data into $5^{\prime} \mathrm{CL}$ structure calculations in the absence of magnesium, hydrogen bonding constraints were added for C10-G31, and hydrogen bonding constraints were retained for $\mathrm{G} 12-\mathrm{U} 29$, but rigidity of the G12-U29 base pair was relaxed.

\section{Chemical shift changes upon addition of magnesium}

Upon addition of magnesium to the $5^{\prime} \mathrm{CL}$, chemical shift changes indicate a return of SLB to its structure when isolated: the splitting of the U29 resonance disappears, the $\mathrm{G} 31$ imino resonance also disappears, and the G11 imino resonance returns to the chemical shift observed in the isolated SLB. Therefore, the above adjustments made to SLB for calculations in the absence of magnesium, were removed for calculations in the presence of magnesium.

Also, two significant changes are observed in SLD. First, a resonance appears for $\mathrm{U} 67$, indicating stabilization of the C51-U67 base pair from the pyrimidine mismatch region of SLD. Although the U67 imino resonance was not observed in the isolated SLD structure analysis (Headey et al. 2007), other NOEs and RDCs clearly indicated the presence of $\mathrm{C} 51-\mathrm{U} 67$ hydrogen bonding in isolated $\mathrm{SLD}$, and so no change was required in the calculations, other than incorporation of the U67 imino RDC.

The second significant change in SLD is alteration of the U66 imino chemical shift by $\sim 0.3 \mathrm{ppm}$ (Fig. 3B). This alteration at the U52-U66 base pair is likely related to the above-mentioned stabilization of the adjacent C51-U67 base pair. This change is also related to a required adjustment made in calculations: In initial calculations of the $5^{\prime} \mathrm{CL}$ structure, both in the presence and in the absence of magnesium, both the U52 and U66 imino RDCs were consistently violated. Non-Watson-Crick base pairs containing two imino protons, such as $\mathrm{U}-\mathrm{U}$ or $\mathrm{G}-\mathrm{U}$ pairs, would be expected to have similar ${ }^{1} \mathrm{H}^{-15} \mathrm{~N}$ RDC values if the base pair is nearly planar. However, the RDC values for the U52-U66 base pair were measured as $38.5 \mathrm{~Hz}$ for U52 and $16.3 \mathrm{~Hz}$ for U66 in the absence of magnesium, and $39.8 \mathrm{~Hz}$ for U 52 and $32.8 \mathrm{~Hz}$ for U66 in the presence of magnesium. In the isolated structure of RV-B14 SLD, the imino bonds for U52 and U66 are nearly coplanar. Therefore, the conformation of the U52-U66 base pair in the $5^{\prime} \mathrm{CL}$ is not consistent with the isolated SLD structure. Therefore, for calculations in both the absence and presence of magnesium, hydrogen bonding constraints were retained for U52-U66, but rigidity of the base pair was relaxed, allowing the structure to adjust to the observed RDCs.

\section{SAXS: global structure of RV-B14 $5^{\prime} \mathrm{CL}$}

Small angle X-ray scattering (SAXS) probes the global shape of biological macromolecules in solution. SAXS is highly complementary to NMR: It is a mid-resolution technique that does not require crystallization or isotope labeling, has no size limitations, and requires low sample quantities. Here, SAXS was used to investigate the global structure of RV-B14 $5^{\prime} \mathrm{CL}$ in the absence and presence of magnesium. The measured radius of gyration $\left(R_{\mathrm{g}}\right)$ and the maximum dimension $\left(D_{\max }\right)$ for the RV-B14 $5^{\prime} \mathrm{CL}$ in the absence of magnesium were 26.8 and $85 \AA$, respectively. Upon the addition of $5 \mathrm{mM} \mathrm{MgCl}$, the $R_{\mathrm{g}}$ and $D_{\max }$ decreased to 22.3 and $70 \AA$, indicating that magnesium triggers a conformational change to a more compact structure, consistent with the NMR results discussed 
above. A Kratky plot ( $q$ vs. $q^{2} \bullet$ I) can be used to assess the overall shape and flexibility of the molecule (Kikhney and Svergun 2015). A bell-shaped Kratky curve indicates a well-folded globular and compact conformation. The Kratky curves in the presence and absence of magnesium are shown in Figure 4A. The RV-B14 $5^{\prime} \mathrm{CL}$ in the absence of magnesium shows a bell-curved shape with a slight plateau at higher $q$ values, whereas the $5^{\prime} \mathrm{CL}$ in the presence of magnesium displays a more evenly distributed plot. This confirms that upon the addition of magnesium the $5^{\prime} \mathrm{CL}$ forms a more well-folded compact conformation. This more compact shape with the presence of magnesium is consistent with the pairwise distribution function $[P(r)]$ plot in Figure 4B.

\section{Full structural calculation: NMR and SAXS}

In the absence of magnesium, 100 three-dimensional structures of RV-B14 $5^{\prime} \mathrm{CL}$ were calculated as described in Materials and Methods, using simulated annealing and rigid body protocol as used by XPLOR-NIH (Schwieters et al. 2003). The eight best final structures selected to represent the conformation have an average pairwise RMSD of $7.735 \AA$ with the A-form helix regions having an RMSD of $6.981 \AA$ (Table 1; Fig. 5A). A similar procedure was performed on RV-B14 $5^{\prime} \mathrm{CL}$ in the presence of $25 \mathrm{mM} \mathrm{MgCl} 2$ with the eight lowest energy structures having an RMSD of $1.812 \AA$, and the A-form helical regions having an RMSD of $1.536 \AA$ (Table 1; Fig. 5B). In the absence of mag- nesium, $5^{\prime} \mathrm{CL}$ adopts an open conformation with SLB and SLD positioned $\sim 90^{\circ}$ apart. In the presence of magnesium, a more compact structure forms with SLB and SLD in close contact and arranged in a parallel form. The positions of SA and SLC in both structures are less defined, at least in part due to the short length of the helices, which renders their position less sensitive to fitting of both the NMR and SAXS data.

\section{Comparison of SAXS-only models with SAXS/NMR- based structures}

Medium-resolution ab initio models of the $5^{\prime} \mathrm{CL}$ shape (Fig. $4 C)$, based only on the SAXS experimental profile, were calculated independently from the XPLOR-calculated structures, using DAMMIF software (Franke and Svergun 2009). In the absence of magnesium, the ab initio model is somewhat $\Lambda$-shaped, but with one leg longer than the other. Overlay of this model with the lowest energy SAXS/NMRbased structure from XPLOR-NIH calculations shows a good fit ( $\chi^{2}$ value of 1.44). The extended leg fits the longest stem-loop (SLD), while the next longest stem-loop, SLB, is fitted into the shorter leg. In this overlay, part of the SLB loop region extends outside of the ab initio model. However, this SLB loop has been shown to be highly dynamic (Warden et al. 2017), and so its position in this figure is somewhat misleading. As a dynamic loop, it can explore many conformations and positions, and so may not give rise to intense density in the ab initio model.
A
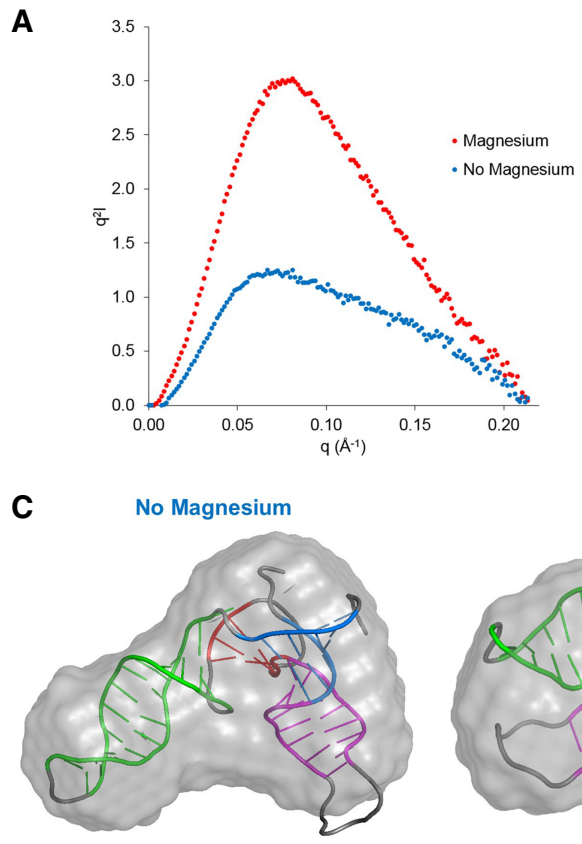

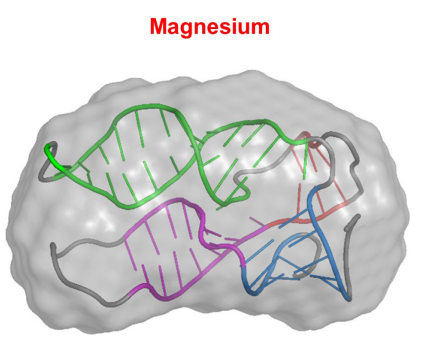

B

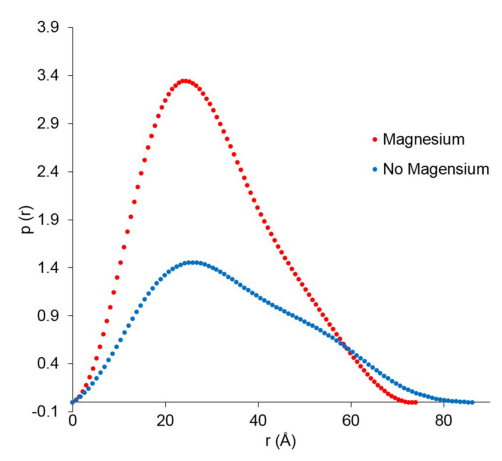

D 3

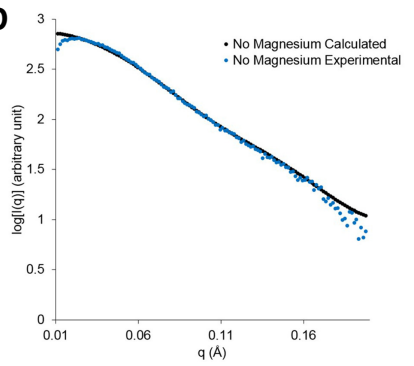

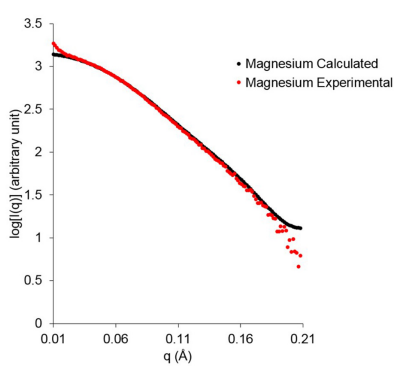

FIGURE 4. SAXS data plots for RV-B14 5'CL. Plots are shown for data in the absence (blue) and presence (red) of magnesium. (A) Kratky plot. (B) Pairwise distance distribution function. (C) SAXS-only ab initio models (gray surface) of $5^{\prime} \mathrm{CL}$ in the absence (left) and presence (right) of magnesium, overlaid with SAXS/NMR-based structures with the helices colored as shown in Figure 1. (D) Overlay of experimental and calculated SAXS profiles. 
TABLE 1. Structural statistics for RV-B14 $5^{\prime} \mathrm{CL}$

\begin{tabular}{lcc}
\hline $\begin{array}{l}\text { RMS constraint/geometry } \\
\text { violations }\end{array}$ & $\begin{array}{c}\text { No } \\
\text { magnesium }\end{array}$ & Magnesium \\
\hline Pf1 RDCs $(\mathrm{Hz})$ & $0.923 \pm 0.309$ & $1.376 \pm 0.113$ \\
SAXS data fit $\left(c^{2}\right)$ & $1.440 \pm 0.002$ & $0.924 \pm 0.001$ \\
Bond lengths $(\AA)$ & $0.005 \pm 0.001$ & $0.004 \pm 0.000$ \\
Bond angles $\left(^{\circ}\right)$ & $0.673 \pm 0.048$ & $0.628 \pm 0.008$ \\
Impropers $\left(^{\circ}\right)$ & $0.382 \pm 0.026$ & $0.380 \pm 0.024$ \\
Ensemble RMSD $(\AA)$ & & \\
Stems & 6.981 & 1.536 \\
SLB and SLD & 5.772 & 0.982 \\
All atoms & 7.735 & 1.812 \\
\hline
\end{tabular}

In the presence of magnesium, the ab initio SAXS structure is more symmetrical and compact. This matches well with the XPLOR-NIH calculated structure in the presence of magnesium ( $\chi^{2}$ value of 0.924 ). The compactness arises when SLB and SLD align and come in to contact with each other. Together, these comparisons of ab initio SAXS-based models with the XPLOR models provide confirmation of structural veracity. Superimposition of the eight lowest energy structures and the SAXS ab initio model is shown in Supplemental Figure S2.

\section{RNA four-way junction: helical arrangement}

RNA junctions are common structural elements found in, for instance, ribosomes, ribozymes, group II introns, and tRNAs. The topology of a junction is characterized by the pattern of coaxial stacking of helices; pairs of helices interacting end-to-end to form one continuous or nearly continuous helix. Based on coaxial stacking patterns, RNA four-way junctions such as $5^{\prime} \mathrm{CL}$ (with four helices from SA, SLB, SLC, and SLD) can be classified into nine different families: families $\mathrm{H}, \mathrm{CH}$, and $\mathrm{CL}$ contain two pairs of coaxial helices; $c K$ and $\pi$ families contain one stacked helix pair each; cW, $\psi, X$, and cX families contain no stacked helices (Laing and Schlick 2009). The RV-B14 5'CL structure in the absence of magnesium shows no clear evidence of coaxial stacking for three of the eight final structures whereas the remaining five present possible stacking between helices SA and SLB.
Doubling present in ${ }^{1} \mathrm{H},{ }^{1} \mathrm{H}-\mathrm{NOESY}$ spectrum, the longer axis length observed in the SAXS ab initio model and the $P(r)$ curve, and the decrease in intensity for the Kratky plot each support the notion that the structure in the absence of magnesium is somewhat extended (not maximally compact). Topologically, the structures fit either the cK or cX classification.

In the presence of magnesium, possible stacking of SA and SLB was also seen in two of the eight final structures, with no stacking evident in the remaining structures. Although somewhat similar coaxial stacking patterns are observed for both conditions, in the presence of magnesium the structure topology is very different, with more evidence of ordered compactness, and with the two longest stems, SLB and SLD, positioned parallel to each other and in close association. Topologically, most of the structures fit the $\mathrm{cW}$ or $\psi$ classification.

\section{DISCUSSION}

Enterovirus replication is a highly conserved mechanism that is initiated by protein-RNA complexes forming upon the $5^{\prime} C L$ RNA. A C-rich region of the SLB loop specifically
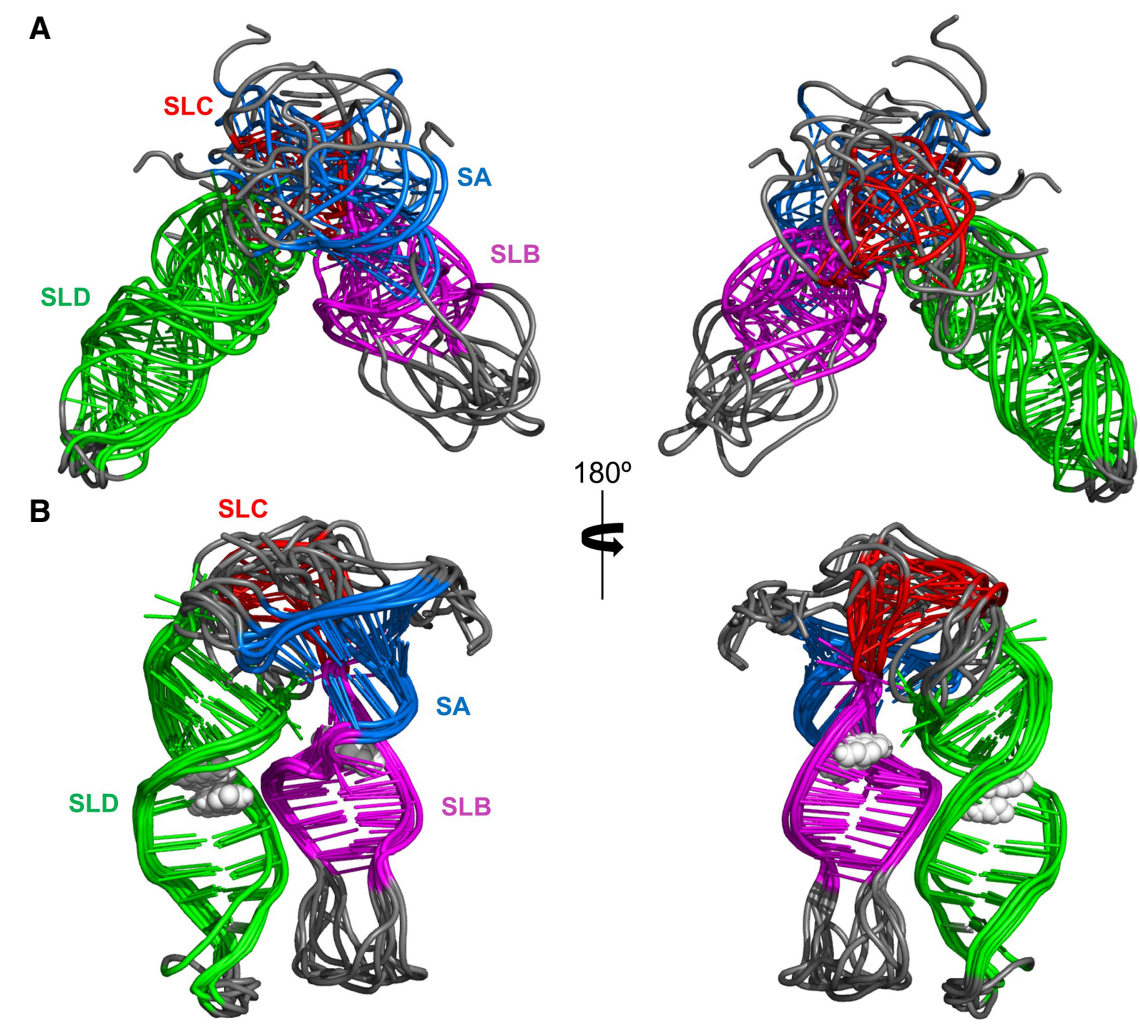

FIGURE 5. Structure of RV-B $145^{\prime} C L$. Superimposition of the eight lowest energy structures of RV-B14 $5^{\prime} C L$ in $(A)$ the absence of magnesium and $(B)$ the presence of magnesium. The loop and terminal regions are colored in gray, the stem regions are colored as in Figure 1 . Atoms from the bases of $U 29, \cup 66$, and $U 67$, each of which show significant changes in NMR spectra upon addition of magnesium, are shown as white spheres. 
binds to the host poly(C)-binding protein (PCBP), facilitating the binding of virus fusion protein $3 C D$ with SLD (Gamarnik and Andino 1998). The PCBP then coordinates with the host poly(A)-binding proteins (PABP) that binds to the A-rich 3'UTR in the virus genome (Barton et al. 2001; Herold and Andino 2001). The PCBP-PABP interaction effectively circularizes the virus genomic RNA, allowing the RNA replicase (3D) to access the $3^{\prime}-$ UTR, where negative strand synthesis initiates. Thus, circularization requires protein-RNA interactions by PCBP, PABP, and 3CD (Gamarnik and Andino 1997; Parsley et al. 1997). The resulting nascent negative strand is then used as a template to create a large number of new positive RNA strands that serve as mRNA and as genetic material for new virus particles. The determination of the three-dimensional structure of RV-B14 $5^{\prime} \mathrm{CL}$, particularly the relative position and orientation of SLB and SLD, upon which PCBP and $3 C D$ assemble, is a vital step toward understanding the replication mechanism of enteroviruses and toward developing therapeutic agents for inhibition of enterovirus replication.

\section{Influence of magnesium}

The present study presents two distinct structures for RV$\mathrm{B} 145^{\prime} \mathrm{CL}$, in the absence and presence of magnesium (Fig. 5). Metal cations play a vital role in RNA folding and stabilization in many biological processes. The positive charge of metal cations can shield the repulsion of the phosphate ions present in the backbone of RNA, allowing RNA to fold into a more stable and compact tertiary conformation. Magnesium is the most often identified cation in RNA structures and is considered the most important divalent cation for RNA stabilization (Tinoco and Bustamante 1999; Gonzalez and Tinoco 2001; Woodson 2005).

In the absence of magnesium, RV-B14 $5^{\prime} \mathrm{CL}$ takes on an open conformation with SLB and SLD approximately perpendicular to one another (Fig. 5A). As discussed in the Results section, some structural dynamics is suggested by relatively broad NMR line shapes, doubling of some imino resonances in the ${ }^{1} \mathrm{H},{ }^{1} \mathrm{H}$ NOESY spectrum and a relatively low intensity in the Kratky plot and $P(r)$ curve (Fig. 4). In contrast, in the presence of magnesium, SLB and SLD move toward each other to form a more compact and more ordered structure (Fig. 5B). Close association of the stems from SLB and SLD results in positioning of the two corresponding loop regions in close proximity (Fig. 5B).

The magnesium-induced association of SLB and SLD suggests that in Figure 1. magnesium binds somewhere along the SLB/SLD interface, helping to screen charge-charge repulsions between the phosphodiester backbones of the two stems. Consistent with this hypothesis, the largest NMR spectral changes in chemical shift upon addition of magnesium (Fig. 3B) occur at nucleotides 11, 12, 29, 62, and 66, each of which are in SLB or SLD. In addition, as discussed previously, doubling of the $\mathrm{U} 29$ resonance disappears and a new peak arises for the $\mathrm{U} 67$ imino resonance.

The observed chemical shift changes seen at bases 11 and 12 upon magnesium addition are related to the destabilization of base pair C10-G31 as discussed in the Results section. The remaining large changes occur in bases 29 , 62,66 , and 67. Three of these bases, U29, U66, and U67, come into close contact with each other in the magnesium structure (Fig. 5B, depicted as spheres). This suggests stable site binding of magnesium very near these three bases.

\section{Fold in absence of magnesium}

Closer examination of the structures in the absence of magnesium reveals the presence of two distinct structural subgroups, differing in the orientation of SA relative to SLB. The first subgroup contains five of the eight structures (Fig. 6A) with the orientation of SA to SLB similar to the relative orientation in the presence of magnesium (Fig. 6B). The remaining three structures effectively reverse the positions of SA and SLC, with SA appearing behind SLC in this view (see Supplemental Fig. S1). Both subgroups fit the NMR and SAXS data, however, the first subgroup (Fig. 6A) has somewhat lower calculated energy, and would require far less structural rearrangement to form the closed structure upon addition of magnesium. The first subgroup shows stacking of SA and SLB, while the second subgroup
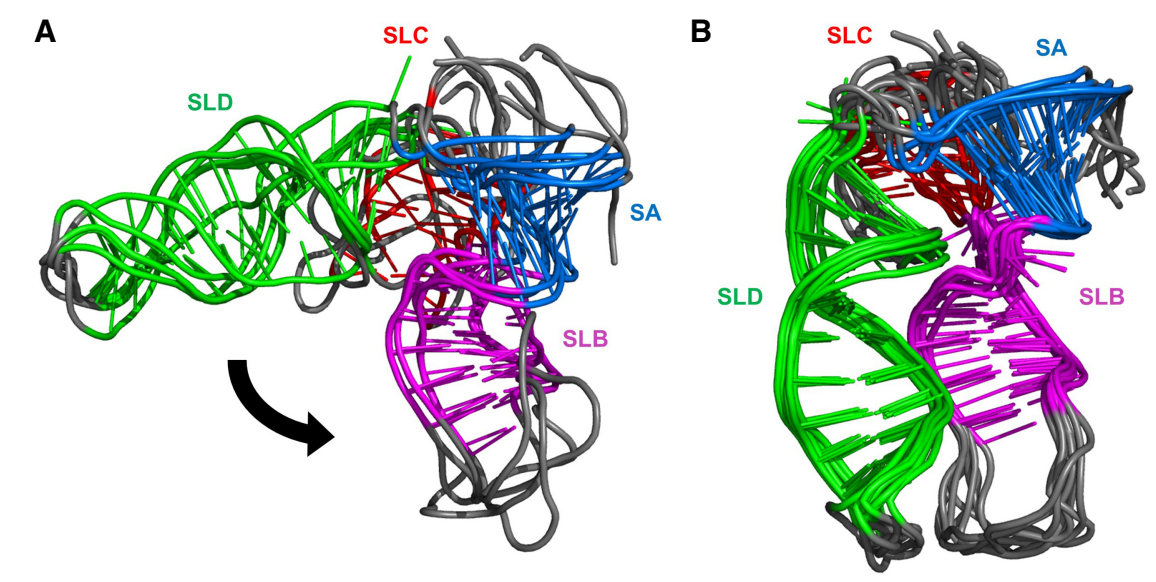

FIGURE 6. Changes in orientation induced by magnesium. (A) Structure in the absence of magnesium. (B) Structure in the presence of magnesium. The black arrow in part $A$ illustrates the change in position of SLD due to the addition of magnesium. Stem regions are colored as 
does not. Topologically, the junction classification of subgroup 1 is cK, while the classification of subgroup 2 is $c X$. The above evidence suggests that the cK structure is the correct fold in the absence of magnesium.

\section{The SAXS/NMR approach}

The combined SAXS/NMR analysis of RNA structure is by now a relatively well-established technique (e.g., Grishaev et al. 2008; Burke et al. 2012; Cornilescu et al. 2016; for recent review, see Mertens and Svergun 2017). Furthermore, when high-resolution structures of the isolated stem-loops are available (via conventional NMR or crystallographic analyses), and when the conservation of these separate structures is verified upon incorporation into the complex, the SAXS/NMR approach is capable of producing high-resolution information. In the present case, prior high-resolution structures are available for the largest two stem-loops (SLB and SLD [Headey et al. 2007; Warden et al. 2017]); which together comprise $61 \%$ of the total cloverleaf. As discussed in the Results section, chemical shift analysis, together with RDC and SAXS fitting, confirm that SLB and SLD structures are largely conserved upon incorporation into the cloverleaf, and pertinent measures were taken to adjust the individual structures to the few data that indicate localized rearrangement.

Information regarding the relative positioning of SLB versus SLD in the cloverleaf is obtained via a combination of orientational information for each helix from RDC analysis and global shape information from SAXS analysis. The combined result is unambiguous: SLB and SLD are oriented well apart from one another, nearly at a right angle, in the absence of magnesium, while they come together to interact closely in the presence of magnesium.

\section{SLB and SLD major grooves and relative helical twist}

Typical A-form RNA contains a narrow (2.4 $\AA$ width) but deep major groove and a wide but shallow minor groove. The narrow major groove restricts protein access for basespecific interactions to the minor groove side. However, the isolated solution structures of RV-B14 SLB and SLD each contain atypically wide and accessible major grooves (9 $\AA$ and $13 \AA$ width, respectively) (Headey et al. 2007; Warden et al. 2017), a feature that is retained upon incorporation into the cloverleaf (see below). In this context, it is interesting to note that magnesium has been shown to help stabilize non-Watson-Crick base pairs (Correll et al. 1997).

The observed accessibility of the SLB major groove is simply due to the brevity of the SLB helix (6-7 base pairs): It contains too few base pairs to form a complete turn (11 base pairs) in order to close off the major groove. The characteristics of SLB are not otherwise unusual.

The SLD helix, on the other hand, contains 12 base pairs when the three central $\mathrm{U}-\mathrm{U}$ and $\mathrm{U}-\mathrm{C}$ pairs are included. This length would be sufficient to close off the major groove if the structure was standard A-form. However, the presence of the non-Watson-Crick pyrimidine mismatch regions in the center of SLD appears to disrupt standard A-form geometry. Non-Watson-Crick base pairs have been shown to induce widened major grooves that serve as recognition sites for protein-RNA interactions (Tanaka et al. 1999; Simon et al. 2015) for instance in the HIV RRE/Rev peptide interaction (Battiste et al. 1996). This can be understood by noting that base-pairing of two pyrimidines requires closer inter-helical approach than does a Watson-Crick pyrimidine-purine base pair, a stress which must distort the helix (same refs as above). Similar widening of the major groove was also reported for SLD from Coxsackievirus B3 (Ohlenschläger et al. 2004) and for a consensus enterovirus SLD sequence (Du et al. 2004).

We find no evidence that this established characteristic of SLD is lost when incorporated into the $5^{\prime} \mathrm{CL}$. As an additional test, we computationally replaced the three central pyrimidine-pyrimidine base pairs in SLD with Watson-Crick pairs, and created a standard A-form SLD computational mutant. Using the same XPLOR-NIH routine, we were unable to find an orientation of the mutant SLD that fits the observed H-N RDCs (removing RDCs from the mismatch region). This, together with the contrasting ability to fit all data using the previously determined SLD structure, with modification only of one $U-U$ base pair orientation as described in the Results section, corroborates that the SLD structure is largely conserved in the cloverleaf.

Next, we analyzed the relative positions of the SLB and SLD accessible major grooves, in the presence of magnesium. The ability of the SAXS/NMR approach to determine the relative helical twist of stem-loops has been previously reported (e.g., Grishaev et al. 2008; Burke et al. 2012). In the present case, the relative helical twist of SLB and SLD orients the two accessible major groove regions in alignment with each other, creating a single accessible groove surface (Fig. 7). This surface is $\sim 30 \AA$ in length, and spans the width of the cloverleaf. Access to this groove surface could potentially stabilize interactions with host and virus proteins during replication, suggesting that it may prove to be an attractive therapeutic target.

\section{Protein-RNA modeling}

In order to begin to understand how the replication complex forms, interactions of the $5^{\prime} \mathrm{CL}$ with the virus $3 \mathrm{C}$ protein and the host PCBP KH1 domain were modeled (Fig. 8). Modeling was based on the previously determined solution structure of isolated RV-B14 SLD complexed with 3C 

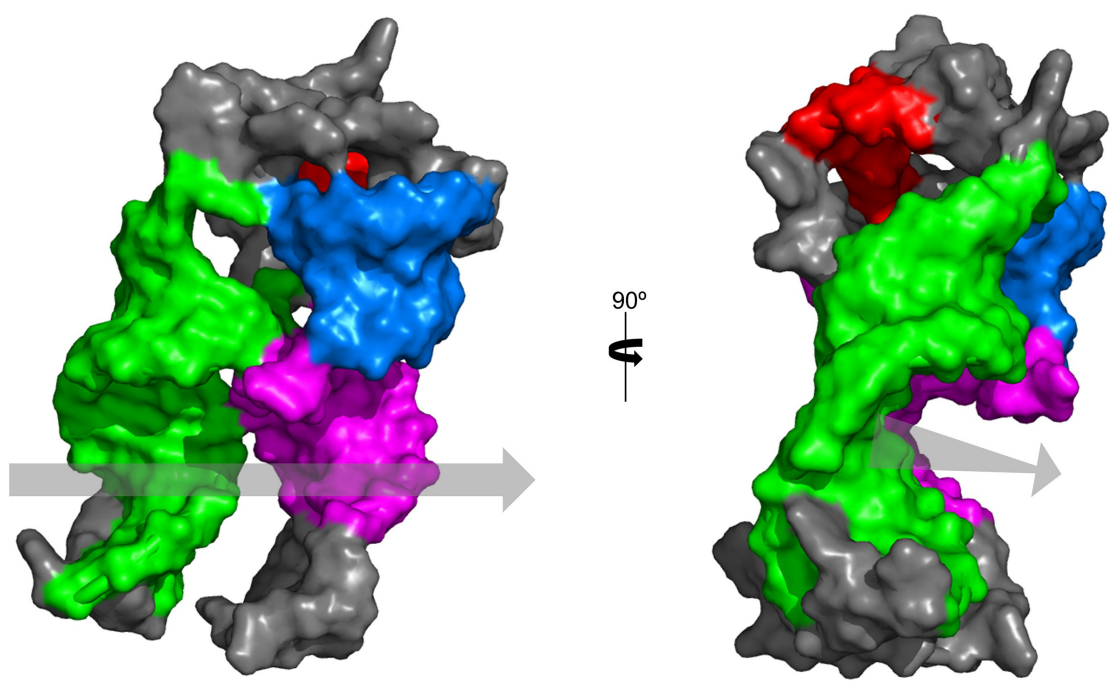

\section{MATERIALS AND METHODS}

\section{RNA preparation}

A DNA transcription template was designed to contain a T7 RNA polymerase promoter followed by a $5^{\prime}$ cis-acting hammerhead ribozyme sequence and 83 nucleotides corresponding to RV-B14 5' CL. The double-stranded DNA plasmid was cloned into the pUC19 vector using the EcoR1 and BamH1 restriction sites. For in vitro transcription, the DNA plasmid was linearized using Bsa1. A natural abundance RNA sample of RV-B14 $5^{\prime} \mathrm{CL}$ was produced by in vitro transcription using T7 RNA polymerase (expressed and purified in house) with RNAPoly reaction buffer (New England Biolabs; $40 \mathrm{mM}$ Tris- $\mathrm{HCl}, 6$ $\mathrm{mM} \mathrm{MgCl}_{2}, 10 \mathrm{mM} \mathrm{DTT}$, and $2 \mathrm{mM}$ spermidine, $\mathrm{pH}$ 7.9), each rNTP at $5 \mathrm{mM}$ (Sigma), $0.02 \mathrm{mg} / \mathrm{mL}$ double-stranded DNA template, and $0.001 \mathrm{unit} / \mathrm{mL}$ pyrophosphatase (Fisher). A $10 \mathrm{~mL}$ transcrip-

(Claridge et al. 2009), and a previously determined structure of the $\mathrm{KH} 1$ domain of PCBP with an oligonucleotide of sequence AACCCTA, which is similar to the sequence in the $5^{\prime} \mathrm{CL}$ SLB C-rich loop (Du et al. 2005). The model in Figure 9 is based on previously determined structure of the poliovirus 3CD fusion protein (Marcotte et al. 2007). In Figure 9, 3D polymerase is positioned in front of the accessible groove. The 3D protein, fused to the $3 \mathrm{C}$ protein that binds SLD, is also positioned near the $\mathrm{KH} 1$ domain of PCBP that interacts with the SLB loop region.

The ability of magnesium to alter the $5^{\prime} \mathrm{CL}$ structure provides evidence that the two structures presented here, the open and closed conformation, could perhaps each be present during different steps in the replication cycle, under the appropriate conditions. Ionic environment, and also other factors, such as protein interactions, may tip this conformational balance. For instance, it is possible that the closed conformation binds PCBP and 3CD, but then circularization via interaction of PCBP with PABP may cause or require a switch to the open conformation. Such a switch to the open conformation could in turn be required to correctly position $3 \mathrm{D}$ at the $3^{\prime} \mathrm{NCR}$ for initiation of negative strand synthesis. Further structural studies performed with the $5^{\prime} \mathrm{CL}$ and replication proteins will however be needed to establish the role, if any, of $5^{\prime} \mathrm{CL}$ conformational switching in the replication mechanism of enteroviruses.
A

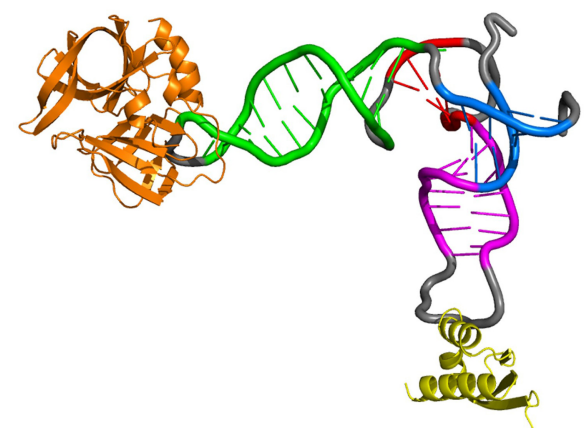

B

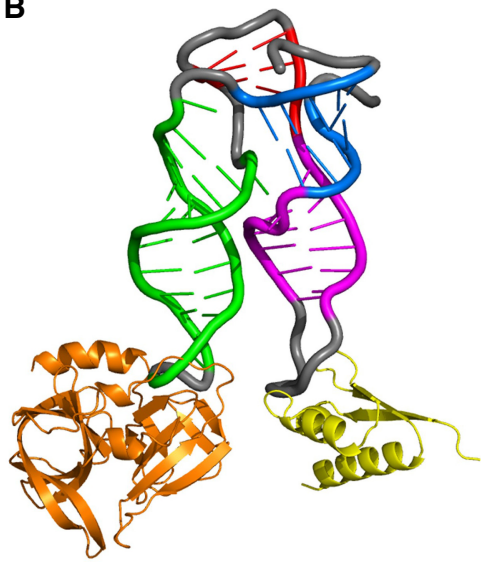

FIGURE 8. RNA-protein interaction modeling. Modeled binding of PCBP KH1 domain (yellow) with SLB and $3 C$ protease (orange) with SLD $(A)$ in the absence and $(B)$ in the presence of magnesium. Stem regions are colored as in Figure 1. 

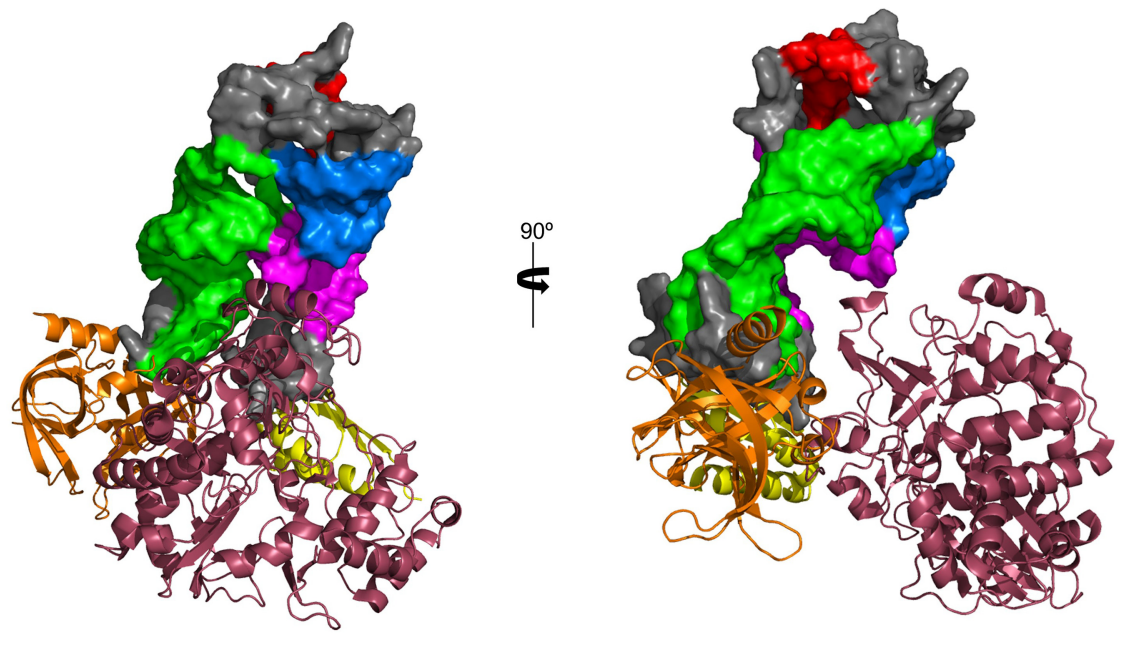

FIGURE 9. RNA-protein interaction modeling. Modeled binding of PCBP KH1 domain (yellow) with SLB and poliovirus $3 C D$ protease (3C: orange, 3D: rose) with SLD, using the $5^{\prime} \mathrm{CL}$ structure in the presence of magnesium. Stem regions are colored as in Figure 1.

spectral noise (Ying et al. 2011). The data for all NMR spectra were processed using NMRPipe (Delaglio et al. 1995) and visualized and analyzed using NMRDraw and NMRViewJ (Norris et al. 2016).

\section{Small-angle X-ray scattering}

SAXS experiments were carried out on a Bruker Nanostar benchtop SAXS system (Bruker AXS) at NMRFAM equipped with a rotating anode $(\mathrm{Cu})$ Turbo $X$-ray Source and a VÅNTEC-2000 $(2048 \times 2048$ pixel) detector. Measurements were carried out in $10 \mathrm{mM} \mathrm{NaP}, 0.1 \mathrm{mM}$ EDTA, $\mathrm{pH} 7.15$ in the absence and presence of $5 \mathrm{mM}$ $\mathrm{MgCl}_{2}$. The buffer used for the SAXS experiments contains $10 \mathrm{mM} \mathrm{NaP}$ and 0.1 mM EDTA, pH 7.15. Samples of $5^{\prime} \mathrm{CL}$ and $5^{\prime} \mathrm{CL}$ with magnesium were clarified by passage through a $0.2 \mathrm{~mm}$ filter before loading into a glass capillary cell. SAXS

using a Biodrop UV-visible spectrophotometer. The RNA was concentrated and buffer exchanged using a Vivaspin spin concentrator (3 kDa cutoff) to a final concentration of $6 \mathrm{mg} / \mathrm{mL}$ in NMR buffer (10 mM sodium phosphate and $0.1 \mathrm{mM}$ EDTA, pH 7.0). The sample was purified with Superdex 200 Increase 10/ $300 \mathrm{GL}$ gel filtration column and further diluted to create $3 \mathrm{mg} /$ $\mathrm{mL}$ and $1.5 \mathrm{mg} / \mathrm{mL}$ samples (SAXS samples). All three samples $(6,3$, and $1.5 \mathrm{mg} / \mathrm{mL})$ were dialyzed thoroughly with degassed NMR buffer. The dialysis buffer was retained for SAXS solvent blank measurements. An additional three samples (6, 3, and $1.5 \mathrm{mg} / \mathrm{mL}$ ) were purified and dialyzed in NMR buffer containing $5 \mathrm{mM} \mathrm{MgCl}_{2}$. A labeled sample of the $5^{\prime} \mathrm{CL}$ was similarly produced using $2 \mathrm{mM}$ each of ${ }^{13} \mathrm{C}$ and ${ }^{15} \mathrm{~N}$-labeled rGTP and rUTP (Cambridge Isotope Laboratories) with $8 \mathrm{mM}$ each of natural abundance rATP and rCTP (Sigma). The sample was divided to produce one labeled sample with $25 \mathrm{mM} \mathrm{MgCl}_{2}$ and one sample containing no $\mathrm{MgCl}_{2}$.

\section{NMR spectroscopy}

A $0.50 \mathrm{mM}$ unlabeled RNA sample in $10 \mathrm{mM}$ sodium phosphate and $0.1 \mathrm{mM}$ EDTA ( $\mathrm{pH} 7.15$ ) containing $90 \% \mathrm{H}_{2} \mathrm{O} / 10 \% \mathrm{D}_{2} \mathrm{O}$ mixture was used for the assignment of exchangeable protons. NMR experiments used for structure calculations were performed on a Bruker Avance-III $750 \mathrm{MHz}$ at the National Magnetic Resonance Facility at Madison (NMRFAM) equipped with a cryoprobe. For assignment of exchangeable proton resonances, ${ }^{1} \mathrm{H},{ }^{1} \mathrm{H}-\mathrm{NOESY}$ spectra in $\mathrm{H}_{2} \mathrm{O}$ were recorded, in the absence and presence of $25 \mathrm{mM}$ magnesium chloride, with mixing times of $150 \mathrm{msec}$ at $5.1^{\circ} \mathrm{C}$ with 256 increments, 2048 data points, 160 scans per fid using excitation sculpting with gradients for water suppression.

Samples with uniform ${ }^{13} \mathrm{C}$ and ${ }^{15} \mathrm{~N}$ enrichment of $\mathrm{G}$ and $\mathrm{U}$ nucleotides, in the absence and presence of $25 \mathrm{mM}$ magnesium chloride, were used for residual dipolar coupling (RDC) measurements. ${ }^{1} \mathrm{H},{ }^{15} \mathrm{~N}$-ARTSY spectra were recorded in isotropic media, and in the presence of $12 \mathrm{mg} / \mathrm{mL}$ Pf1 filamentous bacteriophage. The error of the RDC measurement was assessed via the ratio of the isotropic and attenuated peak intensities compared to the data were collected at three concentrations $1.5,3$, and $6 \mathrm{mg} /$ $\mathrm{mL}$. No significant inter-particle interactions were observed for any of the concentrations. The $3 \mathrm{mg} / \mathrm{mL}$ data was used for model calculation. The sample-to-detector distance was set at $\sim 1 \mathrm{~m}$, allowing for the detection range: $0.012>q>0.25 \AA^{-1}$. Forty microliters of RNA and buffer samples were loaded separately into a capillary cell with $1 \mathrm{~mm}$ diameter, and scattering data were collected for $4 \mathrm{~h}$. The ATSAS software suite (Petoukhov et al. 2012) was used to process the SAXS data. The $R_{\mathrm{g}}$ for each sample was determined by using the Guinier approximation in the $q$ range $\left(q_{\max } \cdot R_{\mathrm{g}}\right)$ $<$ 1.3. Pairwise distance distribution functions $[P(r)]$ were obtained using the GNOM software (Svergun 1992). The output from GNOM was then used in conjunction with DAMMIF (Franke and Svergun 2009) to generate 20 independent ab initio dummy atom models to assess the molecular shape of each sample. No symmetries were enforced during the calculations. Most of the models exhibited excellent agreement with experimental data and had a normalized spatial discrepancy (NSD) $<1$. CRYSOL software (Svergun et al. 1995) was used to compare the $5^{\prime} \mathrm{CL}$ structures with experimental SAXS data. Supcomb software (Kozin and Svergun 2001) was used to superimpose the $5^{\prime} \mathrm{CL}$ structures on to the SAXS ab initio dummy atom models. The $V_{c}$ approach was used for the molecular weight calculation from the SAXS data (Rambo and Tainer 2013). The detailed data acquisition and analysis parameters are listed in Supplemental Table S1.

\section{NMR/SAXS-based structure calculation and refinement}

A total of 2000 preliminary structural models for RV-B14 5' CL were generated using MC-Sym (Parisien and Major 2008). The MC-Sym models were built using reference pdbs for each domain of the $5^{\prime} \mathrm{CL}$, which consisted of the previously determined structures of RV-B14 SLB (Warden et al. 2017) and SLD (Huang et al. 2001; Headey et al. 2007; Claridge et al. 2009) together with SA and SLC structures generated using RNAComposer (Popenda et al. 2012), the latter two based on secondary structure prediction 
and confirmed via assignment of imino proton peaks in the above ${ }^{1} \mathrm{H},{ }^{1} \mathrm{H}-\mathrm{NOESY}$ spectra of the $5^{\prime} \mathrm{CL}$. For the nonmagnesium data, the 2000 models were filtered down to 500 models by comparing $20{ }^{1} \mathrm{H}-{ }^{15} \mathrm{~N}$ experimental RDC versus calculated RDC values determined using PALES (Zweckstetter 2008). The 500 models were subject to $\chi^{2}$ goodness-of-fit analysis between the experimental and the calculated SAXS profile, with the 10 structures having the lowest $\chi^{2}$ values $\left(\chi^{2}<15.1\right)$ taken as preliminary structures to begin XPLOR-NIH (Schwieters et al. 2003) calculations. The procedure was repeated for the data in the presence of magnesium, and 10 best structures with the lowest $\chi^{2}$ value $\left(\chi^{2}<16.5\right)$ were chosen for further refinement with XPLOR-NIH (Schwieters et al. 2003).

In the case of the nonmagnesium sample, for each of the 10 preliminary pdbs, 10 refined structural models were calculated using a simulated annealing and rigid body refinement protocol in XPLOR-NIH (Schwieters et al. 2003) that incorporated both the NMR and SAXS data with floating alignment tensor. In initial calculations in the absence of magnesium, the stem regions of the SA (A5:G9 and C75:U79), SLB (C10:G16 and C25:G31), SLC (A32:C34 and G40:U42) and SLD (U47:C57 and G61:A71) structures were held rigid and contained hydrogen bond constraints, while the nucleotides in the loop and junction regions were given torsional degrees of freedom along with two other nucleotides whose ${ }^{1} \mathrm{H}$ imino resonances were not visible in the $2 \mathrm{D}{ }^{1} \mathrm{H},{ }^{1} \mathrm{H}$ NOESY (G46 and U80). For final calculations, rigidity was removed for nucleotides U52, U66, G12, and U29; however, hydrogen bond constraints for these were retained, as described further in the Results section. In the presence of magnesium, based upon similar imino assignments and NOEs, the regions of the stemloops held rigid were the same as the initial calculations above for the absence of magnesium, with the following exceptions: nucleotides U52, U66, C10, and G31. The hydrogen bond constraints were retained for U52 and U66, but were removed for $\mathrm{C} 10$ and $\mathrm{G} 31$, as described further in the Results section.

In simulated annealing calculations, the initial annealing temperature was set to $3000 \mathrm{~K}$ with a final temperature of $25 \mathrm{~K}$. The force constants for hydrogen bond constraints were ramped from 2 to $50 \mathrm{kcal} \mathrm{mol}^{-1} \AA^{-2}$ and from 0.02 to $5 \mathrm{kcal} \mathrm{mol}^{-1} \mathrm{rad}^{-2}$ for RDC constraints. In the case of no magnesium, the structures were refined with 105 SAXS data points $\left(0.03<q<0.18 \AA^{-1}\right)$ using 20 one-bond ${ }^{1} \mathrm{H}-{ }^{15} \mathrm{~N}$ RDCs, 50 planarity constraints, 124 hydrogen bond-derived constraints along with SAXS data and rigid body minimization in XPLOR-NIH (Schwieters et al. 2003). From the resulting 100 total refined structures, the eight lowest energy structures found with no RDC violations greater than $3 \mathrm{~Hz}$ and SAXS $\chi^{2}$ value of 1.44 or less were taken as the final ensemble, with a pairwise RMSD of $7.735 \AA$ (Fig. 5A). Similarly, from the 100 refined structures in the presence of magnesium, eight structures were found with no RDC violations greater than $3 \mathrm{~Hz}$ and SAXS $\chi^{2}$ value of 0.924 or less. These eight structures were taken as the final structural ensemble in the presence of magnesium, with an average pairwise RMSD of $1.812 \AA$. The constraint and geometry calculations for each condition are shown in Table 1.

\section{SUPPLEMENTAL MATERIAL}

Supplemental material is available for this article.

\section{ACKNOWLEDGMENTS}

We thank John Markley. This study made use of NMR and SAXS instruments at the National Magnetic Resonance Facility at Madison, which is supported by National Institutes of Health grant P41GM103399 (NIGMS). NMR equipment was purchased with funds from the University of Wisconsin-Madison; the National Institutes of Health (P41GM103399, S10RR02781, S10RR08438, S10RR023438, S10RR025062, and S10RR029220); the National Science Foundation (DMB-8415048, OIA-9977486, and BIR9214394); the National Institutes of Health R35GM118131 to S.E.B.; and the United States Department of Agriculture. This work was supported by startup funds and Program for Undergraduate Research and Scholarship grants from Old Dominion University.

Received November 1, 2018; accepted December 19, 2018.

\section{REFERENCES}

Agol VI, Paul AV, Wimmer E. 1999. Paradoxes of the replication of picornaviral genomes. Virus Res 62: 129-147. doi:10.1016/ S0168-1702(99)00037-4

Andino R, Rieckhof GE, Baltimore D. 1990. A functional ribonucleoprotein complex forms around the $5^{\prime}$ end of poliovirus RNA. Cell 63: 369-380. doi:10.1016/0092-8674(90)90170-J

Andino R, Rieckhof GE, Achacoso PL, Baltimore D. 1993. Poliovirus RNA synthesis utilizes an RNP complex formed around the $5^{\prime}$ end of viral RNA. EMBO J 12: 3587-3598. doi:10.1002/j.14602075.1993.tb06032.x

Barton DJ, O'Donnell BJ, Flanegan JB. 2001. 5' cloverleaf in poliovirus RNA is a cis-acting replication element required for negativestrand synthesis. EMBO J 20: 1439-1448. doi:10.1093/emboj/ 20.6.1439

Battiste JL, Mao H, Rao NS, Tan R, Muhandiram DR, Kay LE, Frankel AD, Williamson JR. 1996. $\alpha$ helix-RNA major groove recognition in an HIV-1 rev peptide-RRE RNA complex. Science 273: 1547-1551. doi:10.1126/science.273.5281.1547

Blyn LB, Swiderek KM, Richards O, Stahl DC, Semler BL, Ehrenfeld E. 1996. Poly $(\mathrm{rC})$ binding protein 2 binds to stem-loop IV of the poliovirus RNA 5' noncoding region: identification by automated liquid chromatography-tandem mass spectrometry. Proc Natl Acad Sci 93: 11115-11120. doi:10.1073/pnas.93.20.11115

Blyn LB, Towner JS, Semler BL, Ehrenfeld E. 1997. Requirement of poly $(\mathrm{rC})$ binding protein 2 for translation of poliovirus RNA. J Virol 71: 6243-6246.

Burke JE, Sashital DG, Zuo X, Wang YX, Butcher SE. 2012. Structure of the yeast U2/U6 snRNA complex. RNA 18: 673-683. doi:10.1261/ rna.031138.111

Claridge JK, Headey SJ, Chow JY, Schwalbe M, Edwards PJ, Jeffries CM, Venugopal H, Trewhella J, Pascal SM. 2009. A picornaviral loop-to-loop replication complex. J Struct Biol 166: 251 262. doi:10.1016/j.jsb.2009.02.010

Cornilescu G, Didychuk AL, Rodgers ML, Michael LA, Burke JE, Montemayor EJ, Hoskins AA, Butcher SE. 2016. Structural analysis of multi-helical RNAs by NMR-SAXS/WAXS: application to the U4/ U6 di-snRNA. J Mol Biol 428: 777-789. doi:10.1016/j.jmb. 2015.11.026

Correll CC, Freeborn B, Moore PB, Steitz TA. 1997. Metals, motifs, and recognition in the crystal structure of a $5 \mathrm{~S}$ rRNA domain. Cell 91: 705-712. doi:10.1016/S0092-8674(00)80457-2 
Delaglio F, Grzesiek S, Vuister GW, Zhu G, Pfeifer J, Bax A. 1995 NMRPipe: a multidimensional spectral processing system based on UNIX pipes. J Biomol NMR 6: 277-293. doi:10.1007/ BF00197809

Du Z, Yu J, Ulyanov NB, Andino R, James TL. 2004. Solution structure of a consensus stem-loop D RNA domain that plays important roles in regulating translation and replication in enteroviruses and rhinoviruses. Biochemistry 43: 11959-11972. doi:10.1021/ bi048973p

Du Z, Lee JK, Tjhen R, Li S, Pan H, Stroud RM, James TL. 2005. Crystal structure of the first $\mathrm{KH}$ domain of human poly(C)-binding protein-2 in complex with a C-rich strand of human telomeric DNA at 1.7 A. J Biol Chem 280: 38823-38830. doi:10.1074/jbc. M508183200

Franke D, Svergun DI. 2009. DAMMIF, a program for rapid ab-initio shape determination in small-angle scattering. J Appl Crystallogr 42: 342-346. doi:10.1107/S0021889809000338

Gamarnik AV, Andino R. 1997. Two functional complexes formed by $\mathrm{KH}$ domain containing proteins with the $5^{\prime}$ noncoding region of poliovirus RNA. RNA 3: 882-892.

Gamarnik AV, Andino R. 1998. Switch from translation to RNA replication in a positive-stranded RNA virus. Genes Dev 12: 2293-2304. doi:10.1101/gad.12.15.2293

Gonzalez RL Jr, Tinoco I Jr. 2001. Identification and characterization of metal ion binding sites in RNA. Methods Enzymol 338: 421-443. doi:10.1016/S0076-6879(02)38231-4

Goodfellow I, Chaudhry Y, Richardson A, Meredith J, Almond JW, Barclay W, Evans DJ. 2000. Identification of a cis-acting replication element within the poliovirus coding region. J Virol 74: 45904600. doi:10.1128/JVI.74.10.4590-4600.2000

Goodfellow IG, Kerrigan D, Evans DJ. 2003. Structure and function analysis of the poliovirus cis-acting replication element (CRE). RNA 9: 124-137. doi:10.1261/rna.2950603

Greenberg SB. 2003. Respiratory consequences of rhinovirus infection. Arch Int Med 163: 278-284. doi:10.1001/archinte.163. 3.278

Grishaev A, Ying J, Canny MD, Pardi A, Bax A. 2008. Solution structure of tRNA ${ }^{\text {Val }}$ from refinement of homology model against residual dipolar coupling and SAXS data. J Biomol NMR 42: 99-109. doi:10.1007/s10858-008-9267-x

Headey SJ, Huang H, Claridge JK, Soares GA, Dutta K, Schwalbe M, Yang D, Pascal SM. 2007. NMR structure of stem-loop D from human rhinovirus-14. RNA 13: 351-360. doi:10.1261/rna.313707

Herold J, Andino R. 2001. Poliovirus RNA replication requires genome circularization through a protein-protein bridge. Mol Cell 7: 581591. doi:10.1016/S1097-2765(01)00205-2

Huang $H$, Alexandrov A, Chen X, Barnes TW III, Zhang H, Dutta K, Pascal SM. 2001. Structure of an RNA hairpin from HRV-14. Biochemistry 40: 8055-8064. doi:10.1021/bi010572b

Jacobson SJ, Konings DA, Sarnow P. 1993. Biochemical and genetic evidence for a pseudoknot structure at the $3^{\prime}$ terminus of the poliovirus RNA genome and its role in viral RNA amplification. J Virol 67: 2961-2971.

Kikhney AG, Svergun DI. 2015. A practical guide to small angle X-ray scattering (SAXS) of flexible and intrinsically disordered proteins. FEBS Lett 589: 2570-2577. doi:10.1016/j.febslet.2015.08.027

Kozin MB, Svergun DI. 2001. Automated matching of high- and lowresolution structural models. J Appl Crystallogr 34: 33-41. doi: $10.1107 /$ S0021889800014126

Laing C, Schlick T. 2009. Analysis of four-way junctions in RNA structures. J Mol Biol 390: 547-559. doi:10.1016/j.jmb.2009.04.084

Le SY, Zuker M. 1990. Common structures of the $5^{\prime}$ non-coding RNA in enteroviruses and rhinoviruses: thermodynamical stability and statistical significance. J Mol Biol 216: 729-741. doi:10.1016/ 0022-2836(90)90395-3
Marcotte LL, Wass AB, Gohara DW, Pathak HB, Arnold JJ, Filman DJ, Cameron CE, Hogle JM. 2007. Crystal structure of poliovirus 3CD protein: virally encoded protease and precursor to the RNA-dependent RNA polymerase. J Virol 81: 3583-3596. doi:10.1128/ JVI.02306-06

Mertens HDT, Svergun DI. 2017. Combining NMR and small angle Xray scattering for the study of biomolecular structure and dynamics. Arch Biochem Biophys 628: 33-41. doi:10.1016/j.abb.2017. 05.005

Norris M, Fetler B, Marchant J, Johnson BA. 2016. NMRFx Processor: a cross-platform NMR data processing program. J Biomol NMR 65: 205-216. doi:10.1007/s10858-016-0049-6

Ohlenschläger $O$, Wöhnert J, Bucci E, Seitz S, Häfner S, Ramachandran R, Zell R, Görlach M. 2004. The structure of the stemloop D subdomain of coxsackievirus B3 cloverleaf RNA and its interaction with the proteinase 3C. Structure 12: 237-248. doi:10.1016/ j.str.2004.01.014

Parisien M, Major F. 2008. The MC-Fold and MC-Sym pipeline infers RNA structure from sequence data. Nature 452: 51-55. doi:10.1038/nature06684

Parsley TB, Towner JS, Blyn LB, Ehrenfeld E, Semler BL. 1997. Poly (rC) binding protein 2 forms a ternary complex with the $5^{\prime}$-terminal sequences of poliovirus RNA and the viral 3 CD proteinase. RNA 3: 1124-1134.

Petoukhov MV, Franke D, Shkumatov AV, Tria G, Kikhney AG, Gajda M, Gorba C, Mertens HD, Konarev PV, Svergun DI. 2012. New developments in the ATSAS program package for small-angle scattering data analysis. J Appl Crystallogr 45: 342-350. doi:10.1107/S0021889812007662

Pilipenko EV, Blinov VM, Romanova LI, Sinyakov AN, Maslova SV, Agol VI. 1989. Conserved structural domains in the $5^{\prime}$-untranslated region of picornaviral genomes: an analysis of the segment controlling translation and neurovirulence. Virology 168: 201-209. doi:10.1016/0042-6822(89)90259-6

Popenda M, Szachniuk M, Antczak M, Purzycka KJ, Lukasiak P, Bartol N, Blazewicz J, Adamiak RW. 2012. Automated 3D structure composition for large RNAs. Nucleic Acids Res 40: e112. doi: 10.1093/nar/gks339

Rambo RP, Tainer JA. 2013. Accurate assessment of mass, models and resolution by small-angle scattering. Nature 496: 477-481. doi:10.1038/nature12070

Rivera VM, Welsh JD, Maizel JV Jr. 1988. Comparative sequence analysis of the $5^{\prime}$ noncoding region of the enteroviruses and rhinoviruses. Virology 165: 42-50. doi:10.1016/0042-6822(88) 90656-3

Schwieters CD, Kuszewski JJ, Tjandra N, Clore GM. 2003. The XplorNIH NMR molecular structure determination package. J Magn Reson 160: 65-73. doi:10.1016/S1090-7807(02)00014-9

Simon B, Masiewicz P, Ephrussi A, Carlomagno T. 2015. The structure of the SOLE element of oskar mRNA. RNA 21: 1444-1453. doi: 10.1261/rna.049601

Svergun DI. 1992. Determination of the regularization parameter in indirect-transform methods using perceptual criteria. J Appl Crystallogr 25: 495-503.

Svergun D, Barberato C, Koch MHJ. 1995. CRYSOL-a program to evaluate $x$-ray solution scattering of biological macromolecules from atomic coordinates. J Appl Crystallogr 28: 768-773. doi: $10.1107 /$ S0021889895007047

Tanaka Y, Fujii S, Hiroaki H, Sakata T, Tanaka T, Uesugi S, Tomita K, Kyogoku Y. 1999. A'-form RNA double helix in the single crystal structure of r(UGAGCUUCGGCUC). Nucleic Acids Res 27: 949955. doi:10.1093/nar/27.4.949

Tinoco I, Bustamante C. 1999. How RNA folds. J Mol Biol 293: $271-$ 281. doi:10.1006/jmbi.1999.3001 
Warden MS, Tonelli M, Cornilescu G, Liu D, Hopersberger LJ, Ponniah K, Pascal SM. 2017. Structure of RNA stem loop B from the picornavirus replication platform. Biochemistry 56: 25492557. doi:10.1021/acs.biochem.7b00141

Woodson SA. 2005. Metal ions and RNA folding: a highly charged topic with a dynamic future. Curr Opin Chem Biol 9: 104-109. doi:10.1016/j.cbpa.2005.02.004
Ying J, Wang J, Grishaev A, Yu P, Wang YX, Bax A. 2011. Measurement of ${ }^{1} \mathrm{H}-{ }^{15} \mathrm{~N}$ and ${ }^{1} \mathrm{H}-{ }^{13} \mathrm{C}$ residual dipolar couplings in nucleic acids from TROSY intensities. J Biomol NMR 51: 89103. doi:10.1007/s10858-011-9544-y

Zweckstetter M. 2008. NMR: prediction of molecular alignment from structure using the PALES software. Nat Protoc 3: 679-690. doi:10.1038/nprot.2008.36 

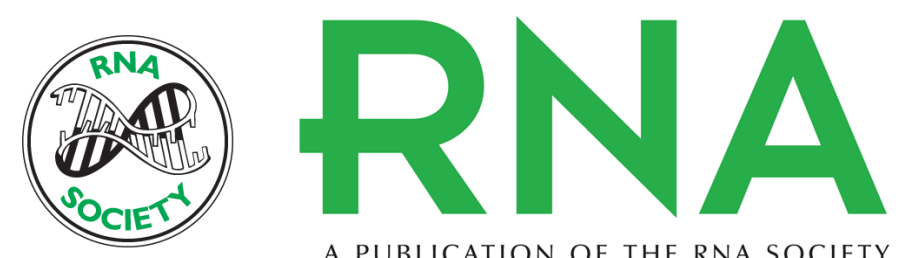

A PUBLICATION OF THE RNA SOCIETY

\title{
Conformational flexibility in the enterovirus RNA replication platform
}

\author{
Meghan S. Warden, Kai Cai, Gabriel Cornilescu, et al.
}

RNA 2019 25: 376-387 originally published online December 21, 2018

Access the most recent version at doi:10.1261/rna.069476.118

\begin{abstract}
Supplemental http://rnajournal.cshlp.org/content/suppl/2018/12/21/rna.069476.118.DC1
Material

References This article cites 51 articles, 15 of which can be accessed free at:

http://rnajournal.cshlp.org/content/25/3/376.full.html\#ref-list-1

Creative This article is distributed exclusively by the RNA Society for the first 12 months after the Commons full-issue publication date (see http://rnajournal.cshlp.org/site/misc/terms.xhtml). After 12 License months, it is available under a Creative Commons License (Attribution-NonCommercial 4.0 International), as described at http://creativecommons.org/licenses/by-nc/4.0/.
\end{abstract}

Email Alerting Receive free email alerts when new articles cite this article - sign up in the box at the Service top right corner of the article or click here. 